\title{
Traumatic Spondyloptosis Causing Complete Transaction of Spinal Cord
}

\author{
Abhay Yadav ${ }^{l}$, Sashmit Sharma². \\ ${ }^{1}$ Department of Orthopaedics, Suvekchya International Hospital and Research Centre \\ Sitapaila, Kathmandu.
}

\begin{abstract}
Traumatic spondyloptosis is a rare presentation and is usually due to very high energy trauma. It is accompanied with cord injury, mostly complete transaction of the cord. In managing such cases special consideration should be given to soft tissues, surrounding structures and organs in the traumatized area. We present a case of traumatic spondyloptosis of D12/L1 in a middle aged gentleman with complete cord transaction.
\end{abstract}

Keywords: cord transaction; spinal arthrodesis; spondyloptosis.

\section{INTRODUCTION}

Traumatic spondyloptosis is defined as greater than $100 \%$ of traumatic subluxation of one vertebral body in coronal or sagittal plane. Fracturedislocations at the dorso-lumbar junction are invariably the consequence of high energy trauma. It is rare, but a severe injury to the vertebral column. In our case, traumatic spondyloptosis of D12/L1 vertebrae resulted in complete transaction of spinal cord. The patient was operated upon successfully with reduction and stabilization with posterior instrumentation. Surgical reconstruction and stabilization allowed for early rehabilitation. Since there was complete cord transaction no neurological recovery was anticipated.

\section{CASE REPORT}

A 45years old gentleman sustained trauma while he slipped coming down the hill and rolled about 100 feets below. Following this traumatic event he had a transient loss of consciousness and developed complete paraplegia. He was unable to move either of his lower limbs. Muscle power was evaluated to be $0 / 5$ in bilateral lower limb and loss of sensation below L1 dermatome.

An AP and lateral plain radiograph demonstrated a complete fracture dislocation of D12/L1. Findings were confirmed by MRI that revealed a fracture line through a D12 and, acomplete fracture dislocation of D12/L1 along with transaction of spinal cord.

On arrival at our hospital, the patient was anemic with hemoglobin of $7.5 \mathrm{mg} / \mathrm{dl}$ and was hypotensive. The patient's condition was stabilized in about Five days. Patient underwent surgery on the sixth day. Reduction of D12/L1 spondyloptosis posteriorly and spinal arthrodesis with instrumentation was performed. During the operation complete cord transaction was noted along with complete anterior and posterior soft tissue disruption. Complete dislocation of D12/L1 vertebrae was obvious on inspection. The spondyloptosis was reduced with the use of pedicle screws at D10 and L2 and a distraction set of external fixator used for wrist. Distraction was continued as decortication of both end plates was done and then apposition was obtained between D12/L1. Reduction was maintained with distraction unit. Bilateral

\section{Correspondence}

Dr. Abhay Yadav

Department of Orthopaedics, Suvekchya International Hospital and Research Centre, Sitapaila, Kathmandu

Email:yabhay@yahoo.com 
NOAJ July-December $2013 \mid$ Vol $3 \mid$ Issue 2

placement of pedicle screw in D10, D11, L2 and single pedicle screw in L1 was done. The pedicle screw was then connected to two parallel rods with a rod to rod connector in between.

Post-operative period was uneventful and the patient received antibiotics for one week. He was discharged on $12^{\text {th }}$ post-operative day. The findings of neurological examination remained unchanged from peroperative evaluation to post-operative evaluation till discharge.

On the last follow-up, which was one year postoperatively, patient is self-ambulatory on a wheel chair, with no neurological recovery.

\section{DISCUSSION \& REVIEW OF} IITERATURE

Spondyloptosis is a severe form of spinal dislocation on which one spinal segment is lodged in the anterior or posterior space of other. Previous case reports of fracture dislocation demonstrated that most of these injuries occur in young patients as a result of high energy trauma and these fracture dislocations are usually accompanied by neurological injury. ${ }^{1-8}$ due to flexion-distraction mechanism. ${ }^{8}$ De oliviera reported ten cases of traumatic retrolisthesis involving the thoraco-lumbar spine at various levels secondary to a direct blow from behind by an automobile. Denis and Burkusreported twelve fracture-dislocations of the thoracic and lumbar spine secondary to a forceful hyperextension mechanism, termed the lumberjack paraplegia injury. ${ }^{9}$ They found disruption of the anterior portion of the annulus and the anterior longitudinal ligament and occasionally avulsion fractures of the vertebral body end plates. They also noted frequent fractures of the posterior-column structures, such as the lamina, the facets and the pars interarticularis. The fracture-dislocation at the thoraco-lumbar junction in our patient demonstrates many features consistent with a mechanism of injury resulting from combined hyperextension and shear forces. Treatment of these severe injuries is difficult and surgeons are reluctant to operate on these cases of completely transacted cord. Treatment options involve conservative treatment with rest,brace and traction to surgical management

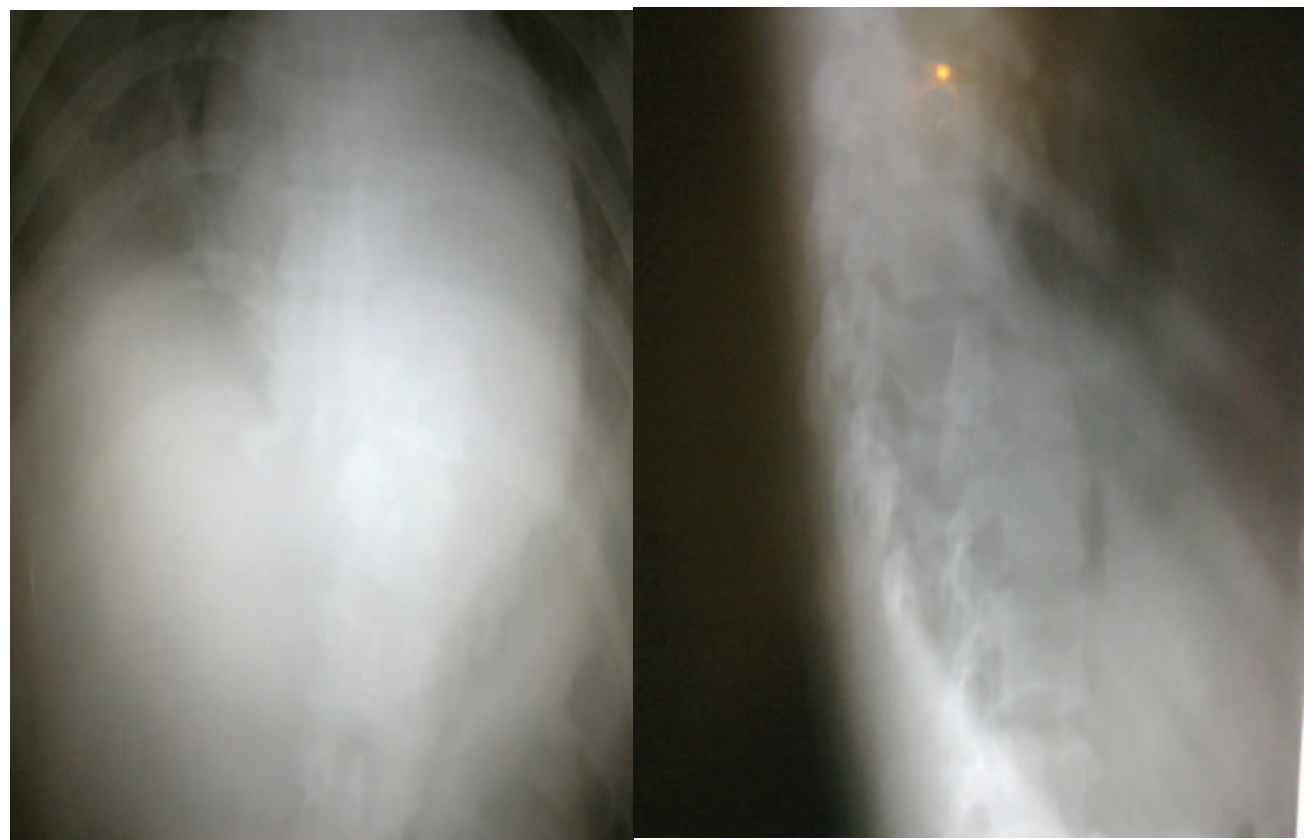

Figure 1. Pre Operative X-Rays

As spondyloptosis is a rare injury to have, literature regarding consensus on mechanism of injury, mode of reduction and treatment options has not been reached. Steinitz et alpostulated that this injury was with operative reduction and internal fixation with instrumentations. Many authors have advocated open reduction and stabilization to facilitate early mobilization and functional rehabilitation. ${ }^{1-4,6,10}$ 
NOAJ July-December $2013 \mid$ Vol $3 \mid$ Issue 2

The high energy nature of these injuries necessitates a careful evaluation of the soft tissue injury and structure surrounding the traumatic area. In our case, special precaution and consideration was given to anterior structures as aorta, venacava and sympathetic chain along with retroperitoneal structures like kidneys and adrenal glands. We believe despite the severe neurological deficits which accompany these high energy injuries, the spine needs to be properly stabilized to relieve pain, provide stability and early rehabilitation.

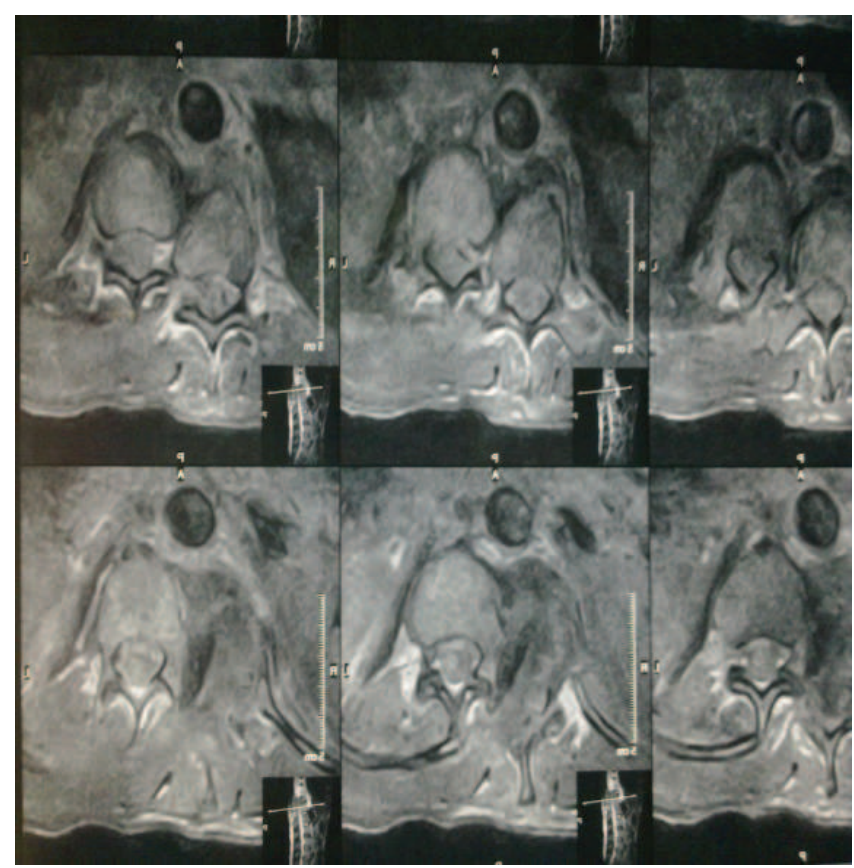

Cohn SL, Keppler L, Akbarnia BA. Traumatic retrolisthesis of the lumbosacral junction. A case report. Spine. $1989 ; 14: 132-4$

3. Finkelstein JA, Hu RW, al-Harby T. Open posterior dislocation of the lumbosacral junction. A case report. Spine. $1996 ; 21: 378-80$

4. Gertzbein SD. Posterior dislocation of the lumbosacral joint: A case report. J Spinal Disord. 1990;3:174-8.

5. Griffin JB, Sutherland GH. Traumatic posterior fracture-dislocation of the lumbosacral joint. J Trauma. 1980;20:426-8.

6. Jackson RH, Quisling RG, Day AL. Fracture and complete dislocation of the thoracic or lumbosacral spine: Report of three cases. Neurosurgery. 1979; 5:250-3.

7. Naude RJ, Govender S, Preston MH. Fracture-dislocation of the lumbosacral spine [letter]. S Afr Med J. $1992 ; 82: 486-7$

8. Steinitz DK, Alexander DI, Leighton RK, O'Sullivan JJ. Late displacement of a fracture dislocation at the lumbosacral junction. A case study. Spine. 1997;22:1024-7.

9. Denis F, Burkus JK. Shear fracture-dislocations of the thoracic and lumbar spine associated with forceful hyperextension (lumberjack paraplegia). Spine. 1992;17:156-61.

10. Samberg LC. Fracture-dislocation of the lumbosacral spine. A case report. J Bone Joint Surg Am. 1975;57:10078 .

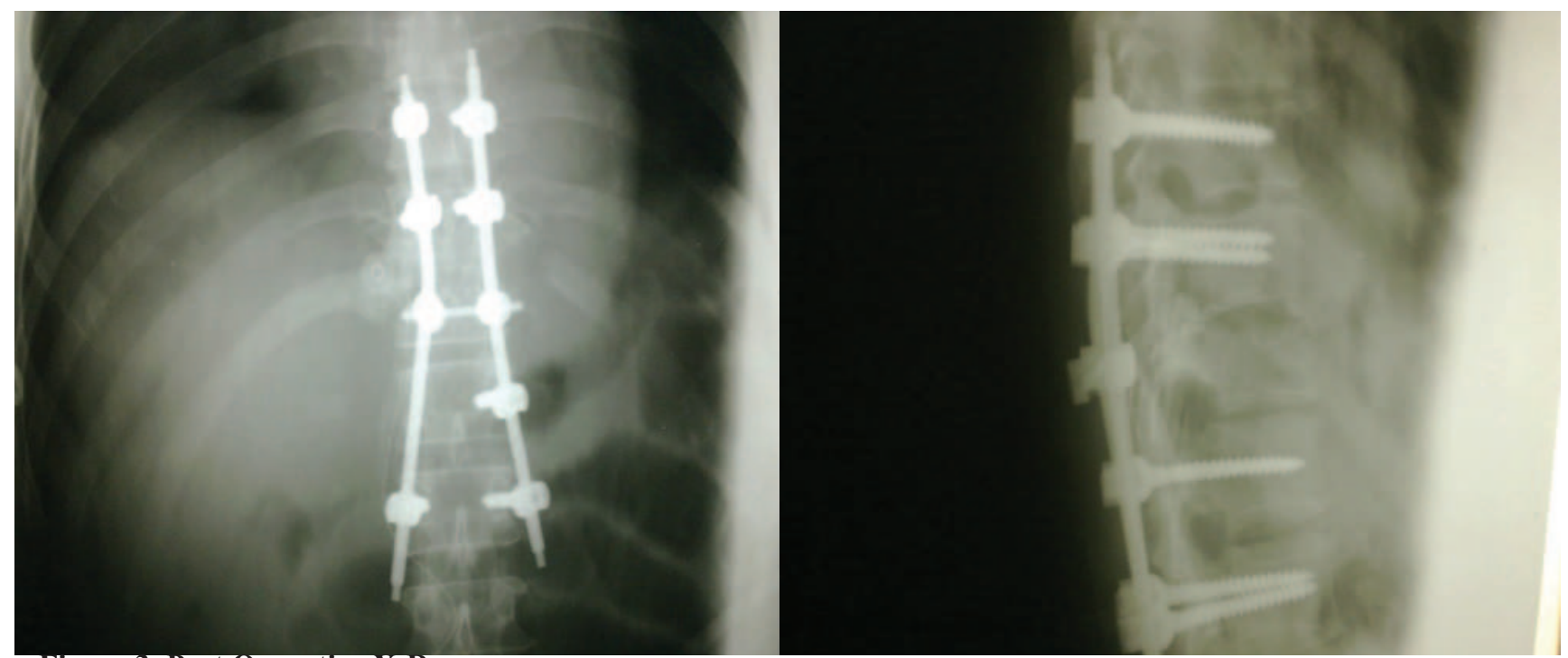

Figure 3. Post Operative X-Rays 